\title{
Erratum to: Antidiabetic Treatment Patterns in a Medicare Advantage Population in the United States
}

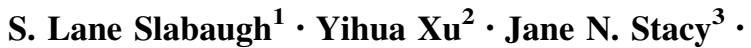 \\ Jean C. Baltz ${ }^{1}$ Yunus A. Meah ${ }^{1} \cdot$ Jean Lian $^{3}$. \\ D. Chad Moretz ${ }^{2} \cdot$ Jonathan R. Bouchard $^{3}$
}

Published online: 27 October 2015

(C) Springer International Publishing Switzerland 2015

Erratum to: Drugs Aging (2015) 32:169-178

DOI 10.1007/s40266-014-0235-8

The numbers of patients listed in each cohort at the top of Table 3 are incorrect.

The correct patient numbers are:

Controlled $(N=109,716)$, uncontrolled $(N=12,188)$, severely uncontrolled $(N=3322)$.

The online version of the original article can be found under doi:10.1007/s40266-014-0235-8.

S. Lane Slabaugh

sslabaugh@humana.com

1 Humana, Inc., 500 West Main Street, Louisville, KY 40202, USA

2 Comprehensive Health Insights, Inc., 515 W. Market St., Louisville, KY 40202, USA

3 Novo Nordisk Pharmaceuticals, Inc., Novo Nordisk Inc., 800 Scudders Mill Road, Plainsboro, NJ 08536, USA 